Check for updates

Cite this: Phys. Chem. Chem. Phys., 2017, 19, 26662

Received 4th August 2017,

Accepted 6th September 2017

DOI: $10.1039 / c 7 c p 05296 k$

rsc.li/pccp

\section{A combined NMR and DFT study of conformational dynamics in lanthanide complexes of macrocyclic DOTA-like ligands $\dagger$}

\author{
Jan Blahut, (D) ${ }^{a}$ Petr Hermann, (DD ${ }^{\star a}$ Zdeněk Tošner $\left(\mathbb{D}^{b}\right.$ and Carlos Platas-Iglesias (D) ${ }^{c}$
}

\section{Introduction}

Since the early 1980s, when the first lanthanide(III) complexes of $\mathrm{H}_{4}$ dota were prepared $\left(\mathrm{H}_{4}\right.$ dota $=1,4,7,10$-tetraazacyclododecane1,4,7,10-tetraacetic acid), ${ }^{1}$ great efforts have been made to understand and describe the conformational properties and dynamics of these and structurally related compounds in solution. The efforts have been mainly driven by the wide range of applications of the complexes in different fields, especially in biology and medicine in various techniques of molecular imaging. In the $[\operatorname{Ln}(\text { dota })]^{-}$complexes and related systems, the metal ion is coordinated to the four nitrogen atoms of the macrocycle,

\footnotetext{
${ }^{a}$ Department of Inorganic Chemistry, Faculty of Science, Charles University, Hlavova 2030/8, Prague 2, 128 43, Czech Republic. E-mail: petrh@natur.cuni.cz

${ }^{b}$ Faculty of Science, Charles University, Hlavova 2030/8, Prague 2, 128 43, Czech Republic

${ }^{c}$ Centro de Investigaciones Cientificas Avanzadas (CICA) and Departamento de Química, Facultade de Ciencias, Universidade da Coruña, 15071 A Coruña, Galicia, Spain

$\dagger$ Electronic supplementary information (ESI) available. See DOI: 10.1039/ c7cp05296k
}

which define the $\mathrm{N}_{4}$ plane, and four oxygen atoms of the pendant arms (referred to as the $\mathrm{O}_{4}$ plane). Usually, an additional coordination position is occupied by a water molecule which caps the $\mathrm{O}_{4}$ plane (Fig. 1). ${ }^{2}$ The relative torsion of the $\mathrm{N}_{4}$

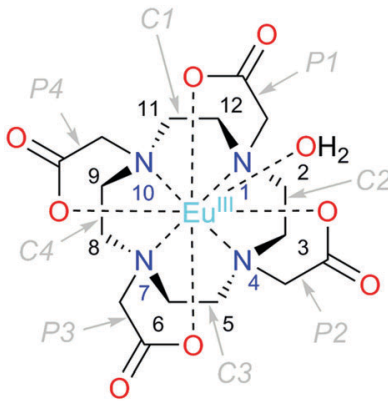

$\left[\mathrm{Eu}(\text { dota })\left(\mathrm{H}_{2} \mathrm{O}\right)\right]^{-}$

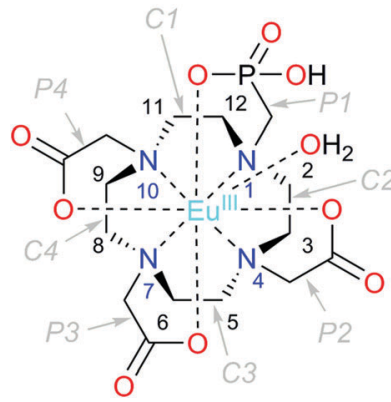

[Eu(Hdo3ap) $\left.\left(\mathrm{H}_{2} \mathrm{O}\right)\right]^{-}$
Fig. 1 Structure of the complexes discussed in this work with an atom and cyclen chelate/pendant arm numbering scheme. The TSAP isomers are depicted in both cases. 
and $\mathrm{O}_{4}$ planes results in two possible orientations of the pendant $\operatorname{arms}(\Delta$ or $\Lambda)$ while the chelate rings of the macrocyclic cyclen unit may adopt two different conformations $(\delta \delta \delta \delta$ or $\lambda \lambda \lambda \lambda)$. As a result, four conformational isomers are possible which are observed as two enantiomeric pairs. One enantiomeric pair $[\Delta(\lambda \lambda \lambda \lambda) / \Lambda(\delta \delta \delta \delta)]$ presents a square antiprismatic (SAP) coordination geometry, whereas the $\Lambda(\lambda \lambda \lambda \lambda) / \Delta(\delta \delta \delta \delta)$ enantiomeric pair adopts a twistedsquare antiprismatic (TSAP) coordination geometry. The exchange between the SAP and TSAP forms can occur via pendant arm rotation or macrocycle chelate ring inversion, while the combination of these two processes results in interconversion between the enantiomers. ${ }^{3}$ While direct enantiomerization has also been postulated, ${ }^{4}$ there is no experimental evidence supporting such a concerted arm-rotation and ring-inversion pathway and, likely, a high activation energy barrier disables it. ${ }^{5}$

The relative abundance of the SAP and TSAP isomers is affected by both the lanthanide(III) ion and the nature of the ligand. Generally, abundance of the SAP isomers increases on going to the right across the lanthanide series while an increase in the steric demand of the pendant arms increases the abundance of the TSAP form. ${ }^{6,7}$ A rational control of the TSAP/SAP ratio in solution favoring one isomer or another is of key importance for many applications of these types of complexes. For instance, TSAP isomers present much faster exchange rates of the coordinated water molecule which, in the case of the $\left[\operatorname{Gd}(\operatorname{dotam})\left(\mathrm{H}_{2} \mathrm{O}\right)\right]^{3+}$ complex (dotam $=$ tetraamide of $\mathrm{H}_{4}$ dota), was shown to be $\sim 50$ times faster than that for the SAP form. ${ }^{8-10}$ The water exchange rate of the coordinated water molecule is an important parameter that affects the efficiency of gadolinium-based contrast agents (CAs) for magnetic resonance imaging (MRI). ${ }^{11}$ A slow water exchange is also critical for the design of MRI contrast agents based on the chemical exchange saturation transfer (CEST) approach. ${ }^{12}$ Because two isomeric forms are present in solution, it is also problematic to use lanthanide complexes with dota-like ligands as paramagnetic probes in protein structure studies, ${ }^{13}$ for the determination of drug binding sites, ${ }^{14}$ and in the design of CEST $^{12,15}$ and PARASHIFT ${ }^{16,17}$ MRI CAs. Other properties are expected to be influenced by this isomerism as well, such as the magnetic anisotropy and symmetry axis orientation in $\mathrm{Dy}^{3+}$ complexes, ${ }^{18}$ or the nuclear relaxation rate of ${ }^{89} \mathrm{Y}$ complexes for application in dynamic nuclear polarization. ${ }^{19}$ Last but not least, isomeric composition affects luminescence properties ${ }^{9}$ and the enantioselectivity of organic reactions using dota-like complexes as catalysts. $^{20}$

NMR spectroscopy is a powerful method that allows determination of isomer composition as well as their interconversion dynamics even in the steady-state. The application of NMR to $\mathrm{Ln}^{3+}$ complexes was reviewed by Babilov, ${ }^{21}$ and the most important methods and their limitations are briefly discussed below. First, the dynamics of the system can be followed by analyzing changes in the line-shape with temperature. Activation energies can be determined either by simple estimation of exchange rates from the coalescence temperature or by more rigorous line-shape fitting. While this method is straightforward and relatively sensitive, it requires a reasonable estimate of the temperature dependence of chemical shifts and transverse relaxation rates. This can be relatively simple for diamagnetic systems but, for paramagnetic complexes, the paramagnetically induced shift and relaxation rates complicate the analysis. Other problems arise from signal overlap and complicated signal behaviour when the exchange process involves more than two sites, which is often the case in dota-like systems. Nevertheless, this technique has been relatively successfully applied for diamagnetic $\mathrm{La}^{3+}$ and $\mathrm{Lu}^{3+}$ complexes and/or employing ${ }^{13} \mathrm{C}$ and ${ }^{31} \mathrm{P}$ NMR spectra which are less affected by paramagnetic effects and are less crowded. ${ }^{7,21-26}$

A second group of NMR techniques is based on selective inversion $^{4,5,24}$ or selective saturation ${ }^{27}$ of a selected NMR resonance and following signal intensities after a delay during which the exchange takes place. These approaches also suffer from signal overlap, especially in complexes of dota derivatives with low symmetry. This problem can be alleviated by using $2 \mathrm{D}$ pulse sequences such as 2D-EXSY. ${ }^{28,29}$ While being very useful for a qualitative description of the dynamics of the system, it is difficult to obtain quantitative results due to the problematic integration of 2D cross-peaks suffering from phase and baseline distortions.

Theoretical calculations can provide detailed information about the mechanism of dynamic processes at the molecular level experienced by lanthanide(III) complexes in solution. Both classical $^{30}$ and $a b$ initio $^{31-33}$ molecular dynamics (AIMD) have been used to investigate lanthanide(III) complexes. However, the parametrization of force fields to be used for $f$-block elements is not a trivial task. In contrast, AIMD offer a robust tool to investigate lanthanide(III) complexes in solution, but their high computational cost rarely allows simulations exceeding a hundred picoseconds. Pollet et al. ${ }^{34}$ used metadynamics to gain information on the water exchange rates of a gadolinium(III) complex, a process that occurs at the time scale of hundreds of nanoseconds. However, conformational dynamics of dota-like complexes take place at the time scale of tens of milliseconds at room temperature, which cannot be reached with the currently available computational resources. Thus, information on the conformational dynamics of lanthanide(III) complexes has been generally obtained by exploring the potential energy surface of the system of interest, which provides the relevant energy minima and transition states and the associated energy profile. ${ }^{35}$ While this approach suffers from some limitations, in particular related to the treatment of solvent effects, it has been shown to provide useful information at the molecular level complementary to experimental studies. ${ }^{36}$

Herein we report thorough NMR analysis of the conformational dynamics of the $\mathrm{Eu}^{3+}$ complexes with the (dota) ${ }^{4-}$ anion and with protonated and deprotonated forms of the (do3ap) ${ }^{5-}$ anion (Fig. 1), which provides exchange rates and activation parameters with unprecedented accuracy. DFT calculations will subsequently be presented to reveal details of the mechanisms responsible for the isomer interconversion.

\section{Results and discussion}

\section{$2.1{ }^{1} \mathrm{H}$ MNR spectra}

The ${ }^{1} \mathrm{H}$ NMR spectrum of $\left[\mathrm{Eu}(\operatorname{dota})\left(\mathrm{D}_{2} \mathrm{O}\right)\right]^{-}$recorded at $5{ }^{\circ} \mathrm{C}$ (Fig. 2) is in agreement with that reported previously. ${ }^{28}$ The spectrum 
a)

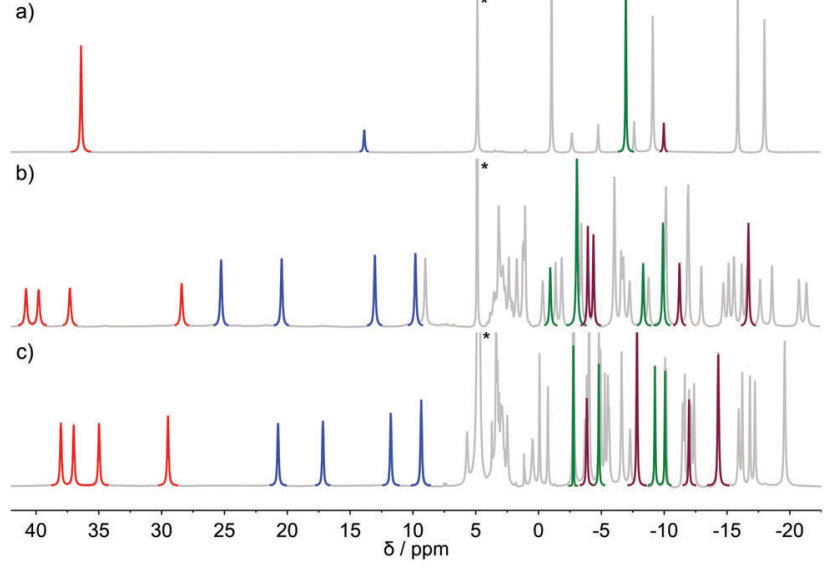

Fig. $2{ }^{1} \mathrm{H}-\mathrm{NMR}$ spectra of: (a) $\left[\mathrm{Eu}(\operatorname{dota})\left(\mathrm{D}_{2} \mathrm{O}\right)\right]^{-}(\mathrm{pD}=7.0) \quad$ (b) $\left[\mathrm{Eu}(\text { do3ap })\left(\mathrm{D}_{2} \mathrm{O}\right)\right]^{2-}(\mathrm{pD}=8.5)$ and $(\mathrm{c})\left[\mathrm{Eu}(\text { Hdo3ap })\left(\mathrm{D}_{2} \mathrm{O}\right)\right]^{-}(\mathrm{pD}=3.6)$ as recorded in $\mathrm{D}_{2} \mathrm{O}$ solution at $5{ }^{\circ} \mathrm{C}$. The signals of the cyclen protons used for ${ }^{1} \mathrm{H}$ 1D-EXSY studies are highlighted in red (SAP axial protons), green (SAP equatorial protons), blue (TSAP axial protons), and purple (TSAP equatorial protons)

consists of two sets of six signals with different intensities, which correspond to the SAP and TSAP isomers, each showing an effective $C_{4}$ symmetry. The equilibrium constant characterizing the isomer equilibrium reaction SAP $\leftrightarrows$ TSAP was determined by integration of signals at $\delta\left({ }^{1} \mathrm{H}\right)=36.32$ and $13.76 \mathrm{ppm}$ yielding $K_{\text {integral }}=0.21$. This value is in good agreement with the values reported previously. ${ }^{3}$ The synthesis and NMR spectra of $\left[\mathrm{Eu}(\text { do3ap })\left(\mathrm{D}_{2} \mathrm{O}\right)\right]^{2-}$ were also published previously; ${ }^{6}$ however no spectral assignments were provided. The phosphonate group of the SAP and TSAP isomers were found to experience protonation processes characterized by $\mathrm{p} K_{\mathrm{a}}$ values of 6.0 (TSAP) and 5.5 (SAP). ${ }^{6}$ Thus, ${ }^{1} \mathrm{H}$ NMR spectra at two $\mathrm{pD}$ values were recorded to investigate the conformational dynamics of both the protonated and non-protonated forms of the complex. The $C_{1}$ symmetry of the two isomers present in solution results in two sets of $24{ }^{1} \mathrm{H}$ NMR signals and two ${ }^{31} \mathrm{P}$ NMR resonances.

The conformational dynamics of $\left[\mathrm{Eu}(\operatorname{dota})\left(\mathrm{D}_{2} \mathrm{O}\right)\right]^{-}$was investigated by focusing on two signals in its ${ }^{1} \mathrm{H}$ NMR spectrum, namely on the macrocyclic chelate ring axial protons that are directed opposite to the pendant arms, and the corresponding geminal equatorial protons (SAP: $36.3 \mathrm{ppm}$ (axial) and $-7.0 \mathrm{ppm}$ (equatorial); TSAP: $13.8 \mathrm{ppm}$ (axial) and $-10.1 \mathrm{ppm}$ (equatorial)). ${ }^{28,37}$ For the $\left[\mathrm{Eu}(\text { Hdo3ap })\left(\mathrm{D}_{2} \mathrm{O}\right)\right]^{-}$and $\left[\mathrm{Eu}(\text { do3ap })\left(\mathrm{D}_{2} \mathrm{O}\right)\right]^{2-}$ complexes, the analogous proton signals were identified using a combination of $2 \mathrm{D}{ }^{1} \mathrm{H}$ EXSY and ${ }^{1} \mathrm{H}-{ }^{1} \mathrm{H}$ COSY experiments (Table $\mathrm{S} 1$ and Fig. S2, ESI $\dagger$ ). The four signals of axial protons of the cyclen unit that point opposite to the pendant arms are observed in the range $\sim 28-40 \mathrm{ppm}$ for the SAP isomers, and between 10 and $25 \mathrm{ppm}$ for the TSAP isomers. These spectral ranges are typical for $\mathrm{Eu}^{3+}$ complexes of $\mathrm{H}_{4}$ dota and dota-tetraamide derivatives. ${ }^{38}$ The equilibrium constants $K_{\text {integral }}$ obtained from the integration of the ${ }^{1} \mathrm{H}$ NMR axial proton resonances (red and blue in Fig. 2) are 0.88 and 1.42 for the $\left[\mathrm{Eu}(\mathrm{Hdo3ap})\left(\mathrm{D}_{2} \mathrm{O}\right)\right]^{-}$and $\left[\mathrm{Eu}(\text { do3ap })\left(\mathrm{D}_{2} \mathrm{O}\right)\right]^{2-}$ complexes, respectively. The increase in the population of the TSAP isomer upon replacing carboxylate group(s) by bulkier phosphonate $\operatorname{arm}(\mathrm{s})$ is well documented, and has been attributed to steric effects. ${ }^{6,7}$

\subsection{D-EXSY experiments}

The conformational dynamics of $\left[\mathrm{Eu}(\operatorname{dota})\left(\mathrm{D}_{2} \mathrm{O}\right)\right]^{-}$, $\left[\mathrm{Eu}(\mathrm{Hdo3ap})\left(\mathrm{D}_{2} \mathrm{O}\right)\right]^{-}$and $\left[\mathrm{Eu}(\text { do3ap })\left(\mathrm{D}_{2} \mathrm{O}\right)\right]^{2-}$ were investigated using an optimized variant of the 1D EXSY experiment. The pulse sequence starts with a selective excitation block realized using a selective refocusing pulse during a spin echo. It is followed by an exchange period $\tau_{M}$ during which the magnetization is stored along the $z$-axis and a spectrum is recorded after the final $90^{\circ}$ pulse (eqn (1)).

$$
90^{\circ}-\delta-180^{\circ}(\mathrm{sel})-\delta-90^{\circ}-\tau_{\mathrm{M}}-90^{\circ}-\mathrm{FID}
$$

Relatively fast relaxation and exchange rates, especially at high temperature, impose a strong requirement to minimize both the duration of an echo, $2 \delta$, and the mixing period $\tau_{\mathrm{M}}$. For slowly relaxing diamagnetic systems, $z$ gradients are used to improve the performance of the selective $180^{\circ}$ pulse, and an inversion pulse (accompanied with gradients) is used during the mixing in order to suppress unwanted magnetization pathways. ${ }^{39}$ For the title paramagnetic samples, the gradients were replaced by a phase cycle that combines EXORCYCLE on the $180^{\circ}$ (sel) pulse, EXORCYCLE on the last $90^{\circ}$ pulse, and a two-step cycle of the first pulse in order to reduce $T_{1}$ relaxation effects by $\pm z$ alternation of the selected magnetization before mixing. In total, the phase cycle has 32 steps that presents no complication for systems with short $T_{1}$ relaxation, allowing fast repetition. Note that the measured magnetization effectively evolves to zero for long mixing times. ${ }^{39}$

Additional considerations should be taken into account when designing the selective refocusing pulse, as both the chemical exchange and relaxation processes take place during the pulse. While the exact description is beyond the scope of this paper, one can qualitatively state that in order to avoid significant loss of signal intensity, the pulse length should be shorter than the characteristic exchange and/or relaxation times. In the present case, the characteristic exchange and relaxation times are approximately $2 \times 10^{-2} \mathrm{~s}$, and thus pulses longer than $\approx 5 \mathrm{~ms}$ should be avoided. On the other hand, short pulses are less selective. Using a Gauss pulse length of $5 \mathrm{~ms}$ results in re-focusing of all resonances within the range of $\approx 200 \mathrm{~Hz}$. This problem is particularly relevant in EXSY experiments when proximate signals are involved in chemical exchange (e.g. undesired partial refocusation of the signal of TSAP axial protons when applying the $180^{\circ}$ (sel) pulse to the resonance of SAP axial protons). Due to this restriction in signal separation, the 1D-EXSY experiments in $\left[\mathrm{Eu}\left(\text { do3ap) }\left(\mathrm{D}_{2} \mathrm{O}\right)\right]^{2-}\right.$ and $\left[\mathrm{Eu}(\mathrm{Hdo3ap})\left(\mathrm{D}_{2} \mathrm{O}\right)\right]^{-}$at all temperatures and in $\left[\mathrm{Eu}(\operatorname{dota})\left(\mathrm{D}_{2} \mathrm{O}\right)\right]^{-}$at temperatures above $5{ }^{\circ} \mathrm{C}$ were performed selecting axial proton signals (6-40 ppm), which are well isolated (Fig. 2). In the case of $\left[\mathrm{Eu}(\operatorname{dota})\left(\mathrm{D}_{2} \mathrm{O}\right)\right]^{-}$at $5{ }^{\circ} \mathrm{C}$, equatorial signals were also used. The same set of experiments was performed for ${ }^{31} \mathrm{P}$ TSAP and SAP signals of $\left[\mathrm{Eu}(\text { do3ap })\left(\mathrm{D}_{2} \mathrm{O}\right)\right]^{2-}$, and $\left[\mathrm{Eu}(\mathrm{Hdo3ap})\left(\mathrm{D}_{2} \mathrm{O}\right)\right]^{-}$at $5{ }^{\circ} \mathrm{C}$ as well.

\subsection{Data analysis}

The exchange rates characterizing the conformational dynamics of the complexes investigated in this work were determined by 
analyzing the evolution of the signal integral as a function of $\tau_{\mathbf{M}}$ through numerical solution of Bloch-McConnell eqn (2),

$$
\begin{gathered}
\frac{\mathrm{d} \boldsymbol{M}}{\mathrm{d} t}=-\boldsymbol{R}\left(\boldsymbol{M}(t)-\boldsymbol{M}_{\mathrm{eq}}\right)+\boldsymbol{k} \boldsymbol{M}(t) \\
\boldsymbol{k}=\left(\begin{array}{cc}
-k_{\text {PendSAP }}-k_{\text {CycleSAP }} & 0 \\
0 & -k_{\text {PendSAP }}-k_{\text {CycleSAP }} \\
k_{\text {PendSAP }} & k_{\text {CycleSAP }} \\
k_{\text {CycleSAP }} & k_{\text {PendSAP }}
\end{array}\right.
\end{gathered}
$$

where $\boldsymbol{M}(t)$ is a vector consisting of $z$-magnetization of $\mathrm{SAP}_{\mathrm{ax}}$, SAP $_{\text {eq }}$, TSAP $_{\text {ax }}$ and TSAP $_{\text {eq }}$ hydrogen atoms; $\boldsymbol{M}_{\text {eq }}$ is its equilibrium value, and $\boldsymbol{R}$ is a diagonal matrix of $R_{1}$ relaxation rates at each site. The exchange matrix $\boldsymbol{k}$ describes all exchange processes that occur in our system and is expressed by eqn (3). In eqn (3), exchange rates $k_{\text {PendSAP }}, k_{\text {CycleSAP }}, k_{\text {PendTSAP }}$ and $k_{\text {CycleTSAP }}$ describe pendant arm rotation and macrocycle inversion experienced by either the SAP or TSAP isomers.

The exchange rates and relaxation times of $\left[\mathrm{Eu}(\operatorname{dota})\left(\mathrm{D}_{2} \mathrm{O}\right)\right]^{-}$ were obtained at $5{ }^{\circ} \mathrm{C}$ from a simultaneous fitting of four datasets measured starting from selected magnetization at the frequencies of the $\operatorname{SAP}_{\mathrm{ax}}(36.3 \mathrm{ppm}), \operatorname{TSAP}_{\mathrm{ax}}(13.8 \mathrm{ppm})$, $\operatorname{SAP}_{\text {eq }}(-7.1 \mathrm{ppm})$ and $\operatorname{TSAP}_{\text {eq }}(-10.1 \mathrm{ppm})$ protons. The four rate constants and the four relaxation rates were used as global variables during the fitting procedure, while $\boldsymbol{M}_{\mathrm{eq}}$ and $\boldsymbol{M}(0)$ were used as local variables for each dataset. Fig. 3 shows the ${ }^{1} \mathrm{H}$ NMR spectra used to obtain one of these datasets by applying the $180^{\circ}$ (sel) pulse at the frequency of the $\mathrm{SAP}_{\mathrm{ax}}$ resonance (36.3 ppm). At short $\tau_{\mathrm{M}}$ values only the signal of the SAP axial protons is observed while the signals of the remaining three protons gradually emerge upon increasing $\tau_{\mathrm{M}}$ as the chemical exchange progresses. The signal evolution of the three resonances encodes kinetic information of a different exchange pathway, as illustrated in Fig. 3. The interconversion between

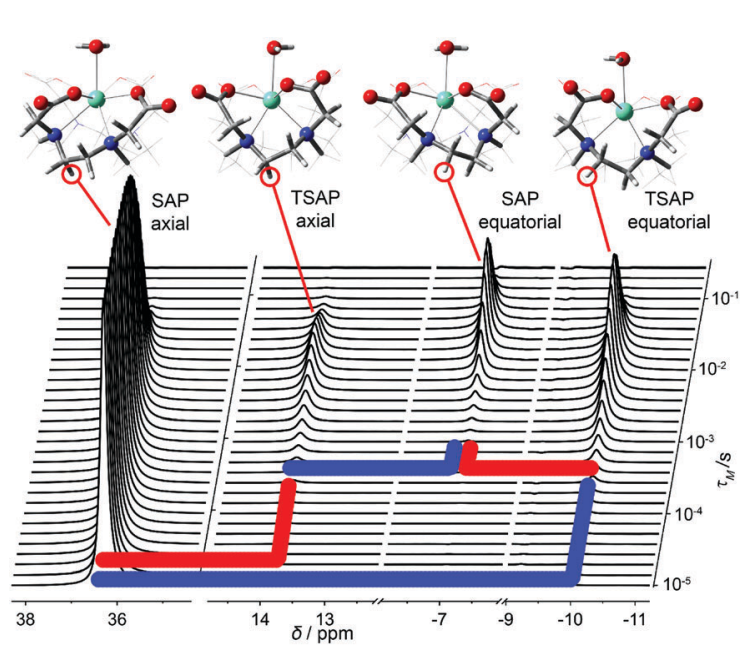

Fig. 3 Series of 1D-EXSY spectra of $\left[\mathrm{Eu}(\operatorname{dota})\left(\mathrm{D}_{2} \mathrm{O}\right)\right]^{-}$recorded by using increasing $\tau_{M}$ values (10 $\mu \mathrm{s}-250 \mathrm{~ms}$ ). The refocusing selective $180^{\circ}$ pulse was applied to the SAP axial resonance. Blue and red lines highlight ring inversion and arm rotation pathways, respectively.
SAP $_{\mathrm{ax}}$ and TSAP $_{\mathrm{ax}}$ protons occurs by rotation of the pendant arms. Interconversion between $\mathrm{SAP}_{\mathrm{ax}} \leftrightarrows \mathrm{TSAP}_{\mathrm{eq}}$ requires the inversion of the cyclen unit, while the $\mathrm{SAP}_{\mathrm{ax}} \leftrightarrows \mathrm{SAP}_{\text {eq }}$ exchange requires both arm rotation and ring inversion. The intensity of the three signals observed due to chemical exchange fades

$\left.\begin{array}{cc}k_{\text {PendTSAP }} & k_{\text {CycleTSAP }} \\ k_{\text {CycleTSAP }} & k_{\text {PendTSAP }} \\ -k_{\text {PendTSAP }}-k_{\text {CycleTSAP }} & 0 \\ 0 & -k_{\text {PendTSAP }}-k_{\text {CycleTSAP }}\end{array}\right)$

away at long $\tau_{\mathbf{M}}$ values due to $T_{1}$ relaxation and the applied phase cycle.

Fig. 4 shows four datasets used to determine the exchange rates and relaxation times in $\left[\mathrm{Eu}(\operatorname{dota})\left(\mathrm{D}_{2} \mathrm{O}\right)\right]^{-}$. A nice fit of the experimental data was obtained by analyzing these four data sets simultaneously. The same procedure was applied to the $\left[\operatorname{Eu}(\text { do3ap })\left(\mathrm{D}_{2} \mathrm{O}\right)\right]^{2-}$ and $\left[\mathrm{Eu}(\mathrm{Hdo3ap})\left(\mathrm{D}_{2} \mathrm{O}\right)\right]^{-}$systems at $5{ }^{\circ} \mathrm{C}$ by using eight datasets. In these cases, the four axial protons of the SAP isomer and the four axial protons of the TSAP isomer were selectively excited (these resonances are well isolated from the remaining ${ }^{1} \mathrm{H}$ NMR signals, see blue and red signals in Fig. 2). The resulting fits are presented in the ESI $\dagger$ (Fig. S4a and S5a). All the exchange and relaxation rates determined from the analysis of the 1D EXSY data are compiled in Table 1.

In agreement with the literature, ${ }^{6}$ the dominant isomer of $\left[\mathrm{Eu}(\text { dota })\left(\mathrm{D}_{2} \mathrm{O}\right)\right]^{-}$is the SAP isomer while the TSAP isomer is the dominant species for $\left[\operatorname{Eu}(\mathbf{d o 3 a p})\left(\mathrm{D}_{2} \mathrm{O}\right)\right]^{2-}$ and the population of SAP and TSAP isomers is very similar for $\left[\mathrm{Eu}(\mathrm{Hdo3ap})\left(\mathrm{D}_{2} \mathrm{O}\right)\right]^{-}$. Therefore, the TSAP $\rightarrow$ SAP interconversion is faster than the $\mathrm{SAP} \rightarrow$ TSAP interconversion in $\left[\mathrm{Eu}(\operatorname{dota})\left(\mathrm{D}_{2} \mathrm{O}\right)\right]^{-}$, while the situation is reversed for $\left[\mathrm{Eu}(\mathbf{d o 3 a p})\left(\mathrm{D}_{2} \mathrm{O}\right)\right]^{2-}$ and the two processes are characterized by similar rates for $\left[\mathrm{Eu}(\mathrm{Hdo3ap})\left(\mathrm{D}_{2} \mathrm{O}\right)\right]^{-}$. The equilibrium constants for the SAP $\leftrightarrows$ TSAP equilibrium
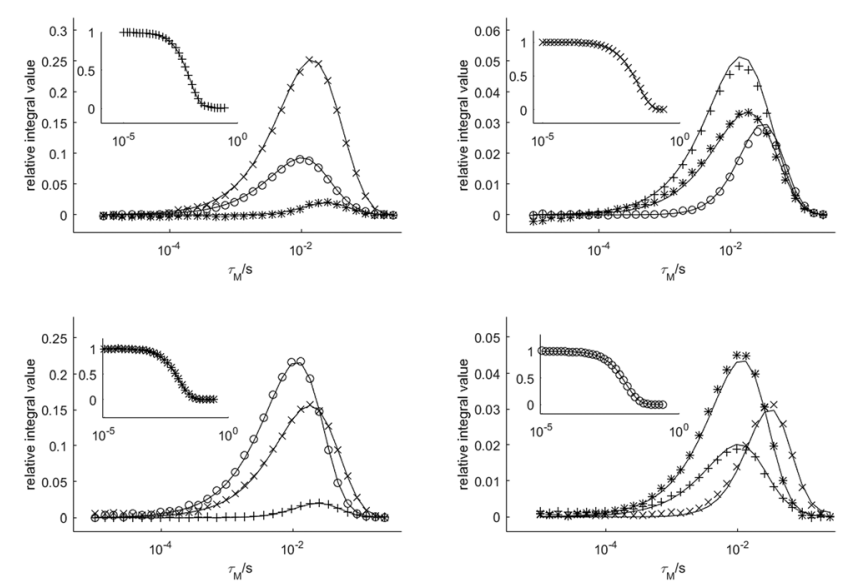

Fig. 4 Relative areas of the four signals of $\left[\mathrm{Eu}(\operatorname{dota})\left(\mathrm{D}_{2} \mathrm{O}\right)\right]^{-}$as a function of the mixing time obtained from $1 \mathrm{D}$-EXSY experiments at $5{ }^{\circ} \mathrm{C}$. The insets show the evolution of the magnetization of the signal to which the refocusing selective $180^{\circ}$ pulse was applied. Symbols: $\operatorname{TSAP}_{a x}(+), \operatorname{SAP}_{\text {eq }}(\times)$, $\operatorname{TSAP}_{\text {eq }}(*), \operatorname{SAP}_{\mathrm{ax}}(O)$. The solid lines represent the simultaneous fit of all four data sets using eqn (2). 
Table 1 Exchange and relaxation rates and equilibrium constants of the $\mathrm{Eu}^{3+}$ complexes determined by the nonlinear fit of ${ }^{1} \mathrm{H}$ 1D-EXSY experimental data at $5{ }^{\circ} \mathrm{C}$ in $\mathrm{D}_{2} \mathrm{O}^{a}$

\begin{tabular}{|c|c|c|c|}
\hline \multirow[b]{2}{*}{ Parameter } & \multicolumn{3}{|l|}{ Anion } \\
\hline & $\operatorname{dota}^{4-}$ & Hdo3ap $^{4-}$ & $\operatorname{do3}_{a p}{ }^{5-}$ \\
\hline$k_{\text {PendSAP }}$ & $5.58(6)$ & $23.2(5)$ & $99.7(3)$ \\
\hline$k_{\text {CycleSAP }}$ & $10.60(7)$ & $19.6(6)$ & $21.0(3)$ \\
\hline$k_{\text {PendTSAP }}$ & $25.80(7)$ & $25.0(5)$ & $71.7(3)$ \\
\hline$k_{\text {CycleTSAP }}$ & $52.30(8)$ & $23.0(6)$ & $15.5(2)$ \\
\hline$K_{\text {EXSY }}$ & $0.207(5)$ & $0.89(9)$ & $1.39(4)$ \\
\hline$K_{\text {integral }}$ & 0.21 & 0.88 & 1.42 \\
\hline$R_{1 \text { Ax } . \mathrm{SAP}}$ & 69.1(1) & $69.4(9)$ & $73.2(4)$ \\
\hline$R_{1 \text { Eq. SAP }}$ & $22.53(7)$ & $20(3)$ & $16(2)$ \\
\hline$R_{1 \mathrm{Ax} . \mathrm{TSAP}}$ & $47.6(2)$ & $54.1(9)$ & $58.9(3)$ \\
\hline$R_{1 \mathrm{Eq} . \mathrm{TSAP}}$ & 18.3(1) & $22(3)$ & $23(2)$ \\
\hline \multicolumn{4}{|c|}{$\begin{array}{l}{ }^{a} \mathrm{k} / \mathrm{s}^{-1} \text { are exchange rates, } R_{1} / \mathrm{s}^{-1} \text { are longitudinal relaxation rates, and } \\
K \text { denotes equilibrium constants calculated as } K_{\text {EXSY }}=\left(k_{\text {PendSAP }}+\right. \\
\left.k_{\text {CycleSAP }}\right) /\left(k_{\text {PendTSAP }}+k_{\text {CycleTSAP }}\right) \text { or determined from integration of the } \\
{ }^{1} \mathrm{H} \text { proton signals of TSAP } / \text { SAP axial protons }\left(K_{\text {integral }}\right) \text {. }\end{array}$} \\
\hline
\end{tabular}

reaction obtained from the exchange rates $\left(K_{\mathrm{EXSY}}=\left(k_{\mathrm{PendSAP}}+\right.\right.$ $\left.\left.k_{\text {CyclesAP }}\right) /\left(k_{\text {PendTSAP }}+k_{\text {CycleTSAP }}\right)\right)$ are in excellent agreement with those obtained from ${ }^{1} \mathrm{H}$ spectral integration (Table 1) and confirms the accuracy of our analysis.

In the case of $\left[\mathrm{Eu}(\mathbf{d o t a})\left(\mathrm{D}_{2} \mathrm{O}\right)\right]^{-}$, the TSAP $\leftrightarrows$ SAP interconversion processes are dominated by the ring inversion mechanism which is approximately twice as fast as the arm rotation (Table 1). The arm rotation and ring inversion processes proceed with comparable rates for $\left[\mathrm{Eu}(\mathrm{Hdo3ap})\left(\mathrm{D}_{2} \mathrm{O}\right)\right]^{-}$. Deprotonation of the phosphonate pendant arm does not have an important effect on the rates characterizing the ring inversion pathway; however, it dramatically accelerates the arm rotation pathway for the TSAP $\rightarrow$ SAP interconversion (from $25.0 \mathrm{~s}^{-1}$ to $71.7 \mathrm{~s}^{-1}$ ), and even more for the reverse process (from $23.2 \mathrm{~s}^{-1}$ to $99.7 \mathrm{~s}^{-1}$, Table 1). These results are in a good agreement with the results of ${ }^{31} \mathrm{P}$ 1D-EXSY experiments where only the sum of arm rotation and ring inversion can be principally detected (see Fig. S6, S7 and Table S5, ESI $\dagger$ ).

The $\mathrm{SAP}_{\mathrm{ax}} \leftrightarrows \mathrm{SAP}_{\mathrm{eq}}$ exchange process represents the mutual interconversion of the SAP enantiomers and requires both arm rotation and inversion of the cyclen chelate rings. Fig. 3 shows that magnetization transfer to $\mathrm{SAP}_{\text {eq }}$ protons occurs with some delay with respect to the $\mathrm{TSAP}_{\mathrm{ax}}$ and $\mathrm{TSAP}_{\text {eq }}$ protons. The same effect can be observed in Fig. 4 for all protons exchanging by racemization with those chosen for the $180^{\circ}$ (sel) pulse. These results indicate that enantiomerization follows concatenated arm rotation and ring inversion mechanisms.

As the EXSY experiments were not designed to measure relaxation rates (their effect is partially suppressed by phase cycling), they were determined with lower accuracy than exchange rates. Nevertheless, in all cases the axial protons present faster relaxation rates than the equatorial ones, which is caused by their shorter distance from the $\mathrm{Eu}^{3+}$ central ion compared to the equatorial protons. ${ }^{40}$ The relaxation rates determined for axial protons of SAP geometries are faster than those observed for TSAP isomers while equatorial protons show comparable relaxation rates in both isomers. This can be attributed, at least in part, to shorter $\mathrm{Eu} \cdots \mathrm{H}_{\mathrm{ax}}$ distances in the SAP isomers (3.849 and $3.931 \AA$ for the SAP and TSAP isomers of $\left[\mathrm{Eu}(\operatorname{dota})\left(\mathrm{D}_{2} \mathrm{O}\right)\right]^{-}$ respectively, according to the DFT calculations presented below), and quite similar distances for the equatorial protons (4.550 and $4.579 \AA$ for the same SAP and TSAP isomers, respectively).

\subsection{Activation parameters}

Variable-temperature ${ }^{1} \mathrm{H}$ 1D-EXSY experiments were also conducted at 15,25 and $35{ }^{\circ} \mathrm{C}$ by applying the same procedures described in the previous section for $5{ }^{\circ} \mathrm{C}$. Measurements at lower temperature were not possible due to hardware and solvent limitations while, at higher temperatures, extensive signal broadening occurs due to chemical exchange. The exchange rates determined at four temperatures $\left(5,15,25\right.$ and $\left.35^{\circ} \mathrm{C}\right)$ were used to determine the activation enthalpy $\Delta H^{\ddagger}$ and activation entropy $\Delta S^{\ddagger}$ of each exchange process using the Eyring equation (4), where all symbols have their usual meaning.

$$
k(T)=\frac{k_{\mathrm{B}} T}{h} \mathrm{e}^{-\frac{\left(\Delta H^{\ddagger}-T \Delta S^{\ddagger}\right)}{R T}}
$$

The activation parameters obtained for the TSAP/SAP exchange processes indicate that arm rotation is driven mainly by enthalpy factors, since entropic contribution is close to zero.

The $\Delta S^{\ddagger}$ values characterizing the arm rotation path of the SAP isomers take values lower than $10 \mathrm{~J} \mathrm{~K}^{-1} \mathrm{~mol}^{-1}$. The reverse process in $\left[\mathrm{Eu}(\text { do3ap })\left(\mathrm{D}_{2} \mathrm{O}\right)\right]^{2-}$ is characterized by a negative activation entropy $\left(\Delta S_{\text {PendTSAP }}^{*}=-17(2) \mathrm{J} \mathrm{K}^{-1} \mathrm{~mol}^{-1}\right)$ that deviates from this trend. Although this difference could be associated with a different mechanism, it can also be associated with an enthalpy-entropy compensation effect due to the simplified model applied, and/or an insufficient temperature range accessible in our experiments. ${ }^{41}$

The activation entropies obtained for the ring inversion process are consistently negative. However, a comparison with data reported for related systems is not straightforward. This is either because of the high uncertainty of the data, ${ }^{29}$ or the different hydration numbers of the SAP and TSAP isomers in the case of the $\mathrm{Lu}^{3+}$-dota complex, which determines the entropy of the transition state. ${ }^{23}$ Despite this, the activation entropy reported for the $\mathrm{La}^{3+}$-dota complex $\left(\Delta S_{\text {CycleTSAP }}^{\ddagger}-21.4 \mathrm{~J} \mathrm{~K}^{-1} \mathrm{~mol}^{-1}\right)$ is consistent with our results. ${ }^{7}$ The strong negative values obtained herein in some cases $\left(\Delta S_{\text {CyclesAP }}^{\ddagger}=-54(11) \mathrm{J} \mathrm{K}^{-1} \mathrm{~mol}^{-1}\right.$ for $\left[\mathrm{Eu}(\text { do3ap })\left(\mathrm{D}_{2} \mathrm{O}\right)\right]^{2-}$ and $\Delta S_{\text {CycleTSAP }}^{\ddagger}=-43(4) \mathrm{J} \mathrm{K}^{-1} \mathrm{~mol}^{-1}$ for $\left.\left[\mathrm{Eu}(\mathrm{Hdo3ap})\left(\mathrm{D}_{2} \mathrm{O}\right)\right]^{-}\right)$are associated with rather low activation enthalpies $\left(\Delta H_{\text {CyclesAP }}^{\ddagger}=45(3) \mathrm{kJ} \mathrm{mol}^{-1}\right.$ for $\left[\mathrm{Eu}(\text { do3ap })\left(\mathrm{D}_{2} \mathrm{O}\right)\right]^{2-}$ and $\Delta H_{\text {CycleTsAP }}^{\ddagger}=49(1) \mathrm{kJ} \mathrm{mol}^{-1}$ for $\left.\left[\operatorname{Eu}(\operatorname{Hdo3ap})\left(\mathrm{D}_{2} \mathrm{O}\right)\right]^{-}\right)$, which again suggests an enthalpy-entropy compensation effect.

\subsection{DFT calculations}

DFT calculations were used to gain an insight into the mechanisms responsible for the conformational dynamics of $\left[\mathrm{Eu}(\operatorname{dota})\left(\mathrm{H}_{2} \mathrm{O}\right)\right]^{-}$, $\left[\mathrm{Eu}(\text { do3ap })\left(\mathrm{H}_{2} \mathrm{O}\right)\right]^{2-}$ and $\left[\mathrm{Eu}(\mathrm{Hdo3ap})\left(\mathrm{H}_{2} \mathrm{O}\right)\right]^{-}$at the molecular level. Following previous studies, we employed the large core relativistic effective pseudopotential of Dolg, ${ }^{42,43}$ which 
includes $46+4 \mathrm{f}^{6}$ electrons of $\mathrm{Eu}^{3+}$ in the core, in combination with Pople's $6-31+G(d, p)$ basis set to describe the ligand atoms. The hybrid meta-GGA functional M06 was used throughout. ${ }^{44}$ Bulk solvent effects were considered by using a polarized continuum model (see computational details below). The two pathways responsible for TSAP/SAP exchange (arm rotation and cyclen inversion) were studied separately as there is no experimental evidence of the composite mechanism.

Geometry optimizations of the $\left[\mathrm{Eu}(\operatorname{dota})\left(\mathrm{H}_{2} \mathrm{O}\right)\right]^{-}$, $\left[\mathrm{Eu}(\text { do3ap })\left(\mathrm{H}_{2} \mathrm{O}\right)\right]^{2-}$ and $\left[\mathrm{Eu}(\mathrm{Hdo3ap})\left(\mathrm{H}_{2} \mathrm{O}\right)\right]^{-}$complexes provided the expected SAP and TSAP isomers as local energy minima. The structure calculated for the SAP isomer of $\left[\mathrm{Eu}(\operatorname{dota})\left(\mathrm{H}_{2} \mathrm{O}\right)\right]^{-}$presents average $\mathrm{Eu}-\mathrm{O}_{\text {carboxylate }}$ and $\mathrm{Eu}-\mathrm{N}$ distances of 2.390 and $2.725 \AA$, respectively, which compare well with the average experimental values obtained from X-ray diffraction measurements $(\mathrm{Eu}-\mathrm{O}=2.394$ and $\mathrm{Eu}-\mathrm{N}=2.680 \AA) .{ }^{45}$ The ring-inversion process responsible for the SAP $\rightarrow$ TSAP interconversion pathway calculated for the three systems is a four-step process; it involves the stepwise inversion of each of the five-membered chelate rings, resulting from the coordination of the macrocyclic unit. This stepwise mechanism is in line with previous studies performed on cyclen-based complexes using HF and DFT methods. ${ }^{5,35,46}$

Several pathways are possible for the inversion of the cyclen unit of $\left[\mathrm{Eu}(\text { dota })\left(\mathrm{H}_{2} \mathrm{O}\right)\right]^{-}$depending on the sequence of ethylenediamine units that change conformation from $\delta$ to $\lambda$. The lowest energy path corresponds to the inversion of cyclen chelate rings following the sequence $\mathrm{C} 2 \rightarrow \mathrm{C} 3 \rightarrow \mathrm{C} 4 \rightarrow \mathrm{C} 1$ (see Fig. 1 for labeling). The calculated activation free energy, as estimated for the transition state (TS) with the highest energy along the minimum energy pathway $\left(\Delta G_{\text {calc }}^{\ddagger}=61.9 \mathrm{~kJ} \mathrm{~mol}^{-1}\right.$, Table 3$)$, is in excellent agreement with the experimental value $\left(\Delta G_{\text {CyclesAP }}^{\ddagger}=62.7 \pm 0.9 \mathrm{~kJ} \mathrm{~mol}^{-1}\right)$. For $\left[\mathrm{Eu}(\text { do3ap })\left(\mathrm{H}_{2} \mathrm{O}\right)\right]^{2-}$ and $\left[\mathrm{Eu}(\mathrm{Hdo3ap})\left(\mathrm{H}_{2} \mathrm{O}\right)\right]^{-}$, the paths with the lowest energy correspond to the sequences $\mathrm{C} 3 \rightarrow \mathrm{C} 1 \rightarrow \mathrm{C} 4 \rightarrow \mathrm{C} 2$ and $\mathrm{C} 2 \rightarrow \mathrm{C} 3 \rightarrow \mathrm{C} 4 \rightarrow \mathrm{C} 1$, respectively, with the inversion of $\mathrm{C} 2$ $\left(\Delta G_{\text {calc }}^{\ddagger}=66.6 \mathrm{~kJ} \mathrm{~mol}^{-1}\right)$ and $\mathrm{C} 3\left(\Delta G_{\text {calc }}^{\ddagger}=60.6 \mathrm{~kJ} \mathrm{~mol}^{-1}\right)$ being the steps with the highest activation energies (Fig. 5). The agreement between the experimental and calculated activation free energies is very good in both cases. However, one should bear in mind that our calculations provide several pathways with very similar activation energies, with 3,12 and 7 paths having activation free energies within $5 \mathrm{~kJ} \mathrm{~mol}^{-1}$ for $\left[\mathrm{Eu}(\operatorname{dota})\left(\mathrm{H}_{2} \mathrm{O}\right)\right]^{-}$, $\left[\mathrm{Eu}(\text { do3ap })\left(\mathrm{H}_{2} \mathrm{O}\right)\right]^{2-}$ and $\left[\mathrm{Eu}(\mathrm{Hdo3ap})\left(\mathrm{H}_{2} \mathrm{O}\right)\right]^{-}$, respectively. Thus, it is likely that several of them can play a role in the $\mathrm{SAP} \rightarrow$ TSAP interconversion process (Fig. 5 and ESI $\dagger$ ).

Our calculations provide negative $\Delta S^{\ddagger}$ values, in agreement with the experimental data (Table 3). An analysis of the different contributions to the total $\Delta S^{\ddagger}$ (ESI $\dagger$ ) indicates that the vibrational contribution is the main factor leading to negative values due to the reduction of intramolecular vibrational frequencies. Inspection of the geometries of the SAP isomers and the transition states responsible for the SAP $\rightarrow$ TSAP interconversion shows that the inversion of the cyclen chelate rings provokes an important lengthening of the $\mathrm{Eu}-\mathrm{N}$ distances. Thus, the largest contribution to the negative $\Delta S^{\ddagger}$ values can be attributed to a reduction of the vibrational frequencies of

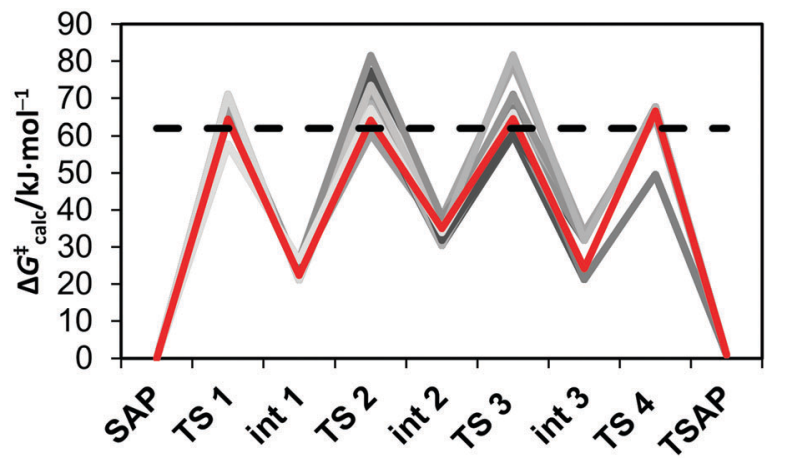

Fig. 5 Energy profile calculated for the cyclen chelate ring inversions in $\left[\mathrm{Eu}(\text { do3ap })\left(\mathrm{H}_{2} \mathrm{O}\right)\right]^{2-}$ at $25^{\circ} \mathrm{C}$. The lowest energy pathway is highlighted in red, while the experimental activation free energy is represented by a black dashed line.

low-frequency modes involving the relative displacement of the lanthanide(III) ion and the nitrogen atoms of the cyclen chelate rings. $^{47}$

According to the calculations, the arm rotation process is synchronous (i.e. the process involves only one transition state) in both $\left[\mathrm{Eu}(\text { dota })\left(\mathrm{H}_{2} \mathrm{O}\right)\right]^{-}$and $\left[\mathrm{Eu}(\mathrm{Hdo3ap})\left(\mathrm{H}_{2} \mathrm{O}\right)\right]^{-}$but follows a stepwise pathway for $\left[\mathrm{Eu}(\text { do3ap })\left(\mathrm{H}_{2} \mathrm{O}\right)\right]^{2-}$. The synchronous mechanisms of $\left[\mathrm{Eu}(\text { dota })\left(\mathrm{H}_{2} \mathrm{O}\right)\right]^{-}$and $\left[\mathrm{Eu}(\mathrm{Hdo3ap})\left(\mathrm{H}_{2} \mathrm{O}\right)\right]^{-}$involve the simultaneous rotation of all four pendant arms. The activation free energies obtained from these calculations are 71.4 $\left(\left[\mathrm{Eu}(\text { dota })\left(\mathrm{H}_{2} \mathrm{O}\right)\right]^{-}\right)$and $85.5\left(\left[\mathrm{Eu}(\mathrm{Hdo3ap})\left(\mathrm{H}_{2} \mathrm{O}\right)\right]^{-}\right) \mathrm{kJ} \mathrm{mol}^{-1}$. These values considerably exceed the experimental values of 64 and $61 \mathrm{~kJ} \mathrm{~mol}^{-1}$ (Table 3), respectively. Nevertheless, the value calculated for $\left[\mathrm{Eu}(\operatorname{dota})\left(\mathrm{H}_{2} \mathrm{O}\right)\right]^{-}$represents a significant improvement with respect to that obtained for $[\mathrm{Lu}(\text { dota })]^{-}$in the gas phase $\left(82.0 \mathrm{~kJ} \mathrm{~mol}^{-1}\right) .^{7}$ Thus, the introduction of bulk solvent effects with a polarized continuum appears to bring the calculated activation energies closer to the experimental values.

Table 2 Activation parameters calculated for TSAP/SAP exchange for the $\mathrm{Eu}^{3+}$ complexes in $\mathrm{D}_{2} \mathrm{O}^{\mathrm{a}}$

\begin{tabular}{llll}
\hline & Anion & & \\
\cline { 2 - 4 } dota $^{4-}$ & Hdo3ap $^{4-}$ & do3ap $^{5-}$ \\
\hline$\Delta H_{\text {PendSAP }}^{\ddagger}$ & $66.0(6)$ & $61.8(7)$ & $58.3(5)$ \\
$\Delta H_{\text {CycleSAP }}^{\ddagger}$ & $58.8(4)$ & $54(1)$ & $45(3)$ \\
$\Delta H_{\text {PendTSAP }}^{\ddagger}$ & $57(1)$ & $61.1(6)$ & $53.4(7)$ \\
$\Delta H_{\text {CycleTSAP }}^{\ddagger}$ & $55(1)$ & $49(1)$ & $59(2)$ \\
$\Delta S_{\text {PendSAP }}^{\ddagger}$ & $7(2)$ & $4(2)$ & $4(2)$ \\
$\Delta S_{\text {CycleSAP }}^{\ddagger}$ & $-13(1)$ & $-26(4)$ & $-54(11)$ \\
$\Delta S_{\text {PendTSAP }}^{\ddagger}$ & $-9(5)$ & $2(2)$ & $-17(2)$ \\
$\Delta S_{\text {CycleTSAP }}^{ \pm}$ & $-14(4)$ & $-43(4)$ & $-10(7)$ \\
$\Delta G_{\text {PendSAP }}^{\ddagger}$ & $64(1)$ & $61(1)$ & $57(1)$ \\
$\Delta G_{\text {CycleSAP }}^{\ddagger}$ & $62.7(9)$ & $62(2)$ & $62(7)$ \\
$\Delta G_{\text {PendTSAP }}^{\ddagger}$ & $61(3)$ & $60(1)$ & $58(1)$ \\
$\Delta G_{\text {CycleTSAP }}^{\ddagger}$ & $59(2)$ & $62(2)$ & $62(4)$
\end{tabular}

${ }^{a} \Delta H^{\ddagger} / \mathrm{kJ} \mathrm{mol}^{-1}, \Delta S^{\ddagger} / \mathrm{J} \mathrm{K}^{-1} \mathrm{~mol}^{-1}$ and $\Delta G^{\ddagger}\left(25^{\circ} \mathrm{C}\right) / \mathrm{kJ} \mathrm{mol}^{-1}$ are activation enthalpy, activation entropy and Gibbs energy (calculated from $\Delta H^{\ddagger}$ and $\Delta S^{\ddagger}$ at $25{ }^{\circ} \mathrm{C}$ ), respectively. 
Table 3 Activation parameters calculated for the ring-inversion process responsible for the SAP $\rightarrow$ TSAP interconversion process of the $\mathrm{Eu}^{3+}$ complexes at $25^{\circ} \mathrm{C}^{a}$

\begin{tabular}{llll}
\hline Anion & $\Delta G_{\text {CyclesAP }}^{\ddagger}$ & $\Delta S_{\text {CyclesAP }}^{\ddagger}$ & $\Delta H_{\text {CyclesAP }}^{\ddagger}$ \\
\hline dota $^{4-}$ & $61.9(62.7)$ & $-3.3(-13)$ & $63.8(58.8)$ \\
Hdo3ap $^{4-}$ & $60.6(62.0)$ & $-8.8(-26)$ & $57.9(54)$ \\
do3ap $^{5-}$ & $66.6(62.0)$ & $-15(-54)$ & $62.2(45)$
\end{tabular}

${ }^{a} \Delta H^{\ddagger} / \mathrm{kJ} \mathrm{mol}^{-1}, \Delta S^{\ddagger} / \mathrm{J} \mathrm{K} \mathrm{K}^{-1} \mathrm{~mol}^{-1}$ and $\Delta G^{\ddagger}\left(25^{\circ} \mathrm{C}\right) / \mathrm{kJ} \mathrm{mol}^{-1}$. The experimental values are provided in parentheses.

This suggests that solvent effects play an important role in the arm rotation process of negatively charged pendant arms.

The polarized continuum model used in this work represents an improvement with respect to previous studies, but it still shows some limitations to account for specific solute-solvent interactions (i.e. hydrogen bonds involving second-sphere water molecules and the negatively charged pendant arms). For instance, it has been shown previously that the explicit inclusion of a few second-sphere water molecules was critical to compute accurate $\mathrm{Ln}-\mathrm{O}_{\text {water }}$ bond distances and ${ }^{17} \mathrm{O}$ hyperfine coupling constants in lanthanide(III) complexes. ${ }^{48,49}$ To test the effect of an explicit second hydration shell, the arm-rotation process on the $\left[\mathrm{Eu}(\text { dota })\left(\mathrm{H}_{2} \mathrm{O}\right)\right]^{-} \cdot 2 \mathrm{H}_{2} \mathrm{O}$ system was investigated. It includes two explicit second-sphere water molecules involved in hydrogen bonds with the coordinated water molecule and oxygen atoms of the carboxylate groups (Fig. S12, ESI $\dagger$ ). The inclusion of two second-sphere water molecules results in a significant shortening of the calculated $\mathrm{Eu}-\mathrm{O}_{\text {water }}$ bond distance from 2.583 to $2.491 \AA$ for the SAP isomer, the latter value being in good agreement with the value observed in the solid state $(2.480 \AA) .{ }^{45}$ The synchronous transition state obtained for this system provides a calculated $\Delta G^{\ddagger}$ value of $60.0 \mathrm{~kJ} \mathrm{~mol}^{-1}$, which is in close agreement with the experimental value of $64(1) \mathrm{kJ} \mathrm{mol}^{-1}$ (Table 3). For $\left[\mathrm{Eu}(\mathrm{Hdo3ap})\left(\mathrm{H}_{2} \mathrm{O}\right)\right]^{-}$, the inclusion of the explicit water molecules also results in the decrease in the arm rotation activation energy $\left(81.9 \mathrm{~kJ} \mathrm{~mol}^{-1}\right)$, but the effect is not as large as for $\left[\mathrm{Eu}(\text { dota })\left(\mathrm{H}_{2} \mathrm{O}\right)\right]^{-}$. However, a similar trend in the $\mathrm{Eu}-\mathrm{O}_{\text {water }}$ bond distance of the SAP isomer was followed; the distances are 2.584 and $2.492 \AA$ for the $\left[\mathrm{Eu}(\mathrm{Hdo3ap})\left(\mathrm{H}_{2} \mathrm{O}\right)\right]^{-}$complex and the $\left[\mathrm{Eu}(\mathrm{Hdo3ap})\left(\mathrm{H}_{2} \mathrm{O}\right)\right]^{-} \cdot 2 \mathrm{H}_{2} \mathrm{O}$ system, respectively.

The energy profile calculated for the stepwise rotation of the pendant arms in $\left[\mathrm{Eu}(\text { do3ap })\left(\mathrm{H}_{2} \mathrm{O}\right)\right]^{2-}$ is shown in Fig. 6 and Table 4 . The first step of the pathway corresponds to the rotation of the phosphonate pendant arm, which changes its coordination mode from mono - to bidentate (Fig. 7). Subsequent rotation of the three acetate pendant arms results in SAP $\rightarrow$ TSAP interconversion. The activation free energy estimated from the energy of the transition state with the highest energy is $42.6 \mathrm{~kJ} \mathrm{~mol}^{-1}$ (Table 5). This value is somewhat lower than the experimental one (57(1) $\mathrm{kJ} \mathrm{mol}^{-1}$, Table 2). We attribute this discrepancy to an overestimation of the stability of the intermediates with the bidentate phosphonate group; this is related to the limitations of continuum solvation models to provide an adequate description of the hydration of the negatively double-charged phosphonate groups. In order to understand this effect, the rate

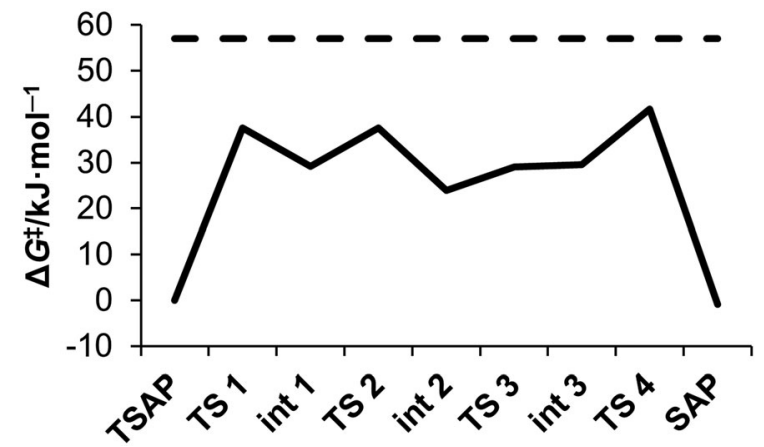

Fig. 6 Calculated energy profile of successive arm rotation of $\left[\mathrm{Eu}\left(\text { do3ap) }\left(\mathrm{H}_{2} \mathrm{O}\right)\right]^{2-}\right.$ at $25{ }^{\circ} \mathrm{C}$ (full line); compared to experimental activation energy $\Delta G$ PिendTSAP (dashed line). For geometry of each intermediate (Int \#) and transition state (TS \#), see the ESI. $\dagger$

Table 4 Calculated energy profile of successive pendant flipping of $\left[\mathrm{Eu}\left(\text { do3ap) }\left(\mathrm{H}_{2} \mathrm{O}\right)\right]^{2-}\right.$ at $25^{\circ} \mathrm{C}$

\begin{tabular}{lc}
\hline Step/intermediate & $a$ \\
\hline TSAP & $\Delta G_{\text {calc }}^{\ddagger} / \mathrm{kJ} \mathrm{mol}^{-1}$ \\
TS 1 & 0.0 \\
Int 1 & 37.5 \\
TS 2 & 29.2 \\
Int 2 & 37.5 \\
TS 3 & 23.9 \\
Int 3 & 29.0 \\
TS 4 & 29.6 \\
SAP & 41.7 \\
TA & -0.9
\end{tabular}

${ }^{a}$ For each step description, see text and ESI; Int \# indicates a stable intermediate between two-step transition states (TS \#).

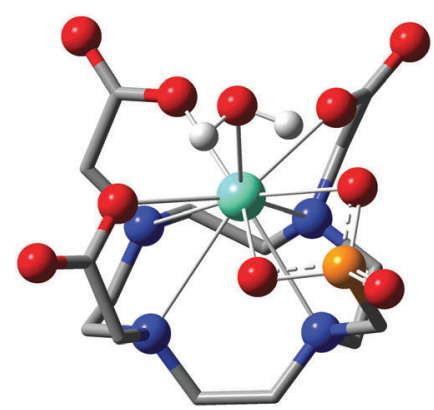

Fig. 7 Calculated molecular structure of the $\left[\mathrm{Eu}(\mathbf{d o 3 a p})\left(\mathrm{H}_{2} \mathrm{O}\right)\right]^{2-}$ intermediate (Int 1) with the bidentate phosphonate group. Color code: black - carbon; white - hydrogen; blue - nitrogen; red - oxygen; orange phosphorus; green - europium. Macrocycle hydrogen atoms are omitted for clarity.

determining step was re-optimized with two second-sphere water molecules. The corresponding activation energy $\left(51.2 \mathrm{~kJ} \mathrm{~mol}^{-1}\right)$ is in reasonable agreement with the experiment. The $\mathrm{Eu}-\mathrm{O}_{\text {water }}$ bond distance of the SAP isomer is 2.633 and $2.593 \AA$ for $\left[\mathrm{Eu}(\text { do3ap })\left(\mathrm{H}_{2} \mathrm{O}\right)\right]^{2-}$ and $\left[\mathrm{Eu}(\text { do3ap })\left(\mathrm{H}_{2} \mathrm{O}\right)\right]^{2-} \cdot 2 \mathrm{H}_{2} \mathrm{O}$ respectively, which is consistent with the trends discussed above.

The results obtained for the arm rotation mechanism show that adding second-sphere water molecules results in a more accurate description of the system. In principle, the model 
Table 5 Calculated free energy of arm rotation $\left(\Delta G_{\text {calc }}^{\ddagger} / \mathrm{kJ} \mathrm{mol}^{-1}\right)$ compared to the related experimental value $\left(\Delta G_{\bar{P}}^{\#}\right.$ endSAP $\left./ \mathrm{kJ} \mathrm{mol}^{-1}\right)$ with $n$ second-sphere water molecules (the free energies are related to the SAP isomers)

\begin{tabular}{llll}
\hline & \multicolumn{2}{l}{ Anion } & \\
\cline { 2 - 4 } Parameter & dota $^{4-}$ & Hdo3ap $^{4-}$ & do3ap $^{5-}$ \\
\hline$\Delta G_{\text {PendSAP }}^{\ddagger}$ & $64(1)$ & $61(1)$ & $57(1)$ \\
$\Delta G_{\text {calc }}^{\ddagger} n=0$ & $71.4^{b}$ & $85.5^{b}$ & $42.6^{c}$ \\
$\Delta G_{\text {calc }}^{\ddagger} n=2$ & $60.0^{b}$ & $81.9^{b}$ & $51.2^{c}$ \\
{$[\operatorname{Lu}(\text { dota) })]^{-}$without $\mathrm{PCM}^{a}$} & 82.0 & - & -
\end{tabular}

${ }^{a}$ Ref. $7 .{ }^{b}$ Synchronous process. ${ }^{c}$ Rate-determining step of successive arm rotation.

could be further improved by increasing the number of explicit second-sphere water molecules. However, our attempts in this direction failed because the increasing number of soft degrees of freedom disables transition state geometry optimization. However, alternative molecular dynamics or metadynamics simulations ${ }^{34,50}$ are not effective enough to reach the long (ms) trajectories required to describe the TSAP $\leftrightarrow$ SAP interconversion.

\subsection{Conclusions}

The dynamics of lanthanide(III) complexes with ligands structurally related to $\mathrm{H}_{4}$ dota in solution is critical for the behaviour of these systems if they are applied as MRI CAs. One of the most important dynamic processes occurring in complexes of the dota-like ligands is the exchange between the SAP and TSAP geometries of the coordination polyhedron. This exchange can occur via pendant arm rotation or cyclen inversion. Though many publications have focused on the description of this complicated motion, the rates of these processes were not measured accurately.

In this work, we determined arm rotation and cyclen inversion rates separately by utilization of a modified EXSY NMR pulse sequence in combination with full Bloch-McConnellbased data analysis. In addition, we also reported the corresponding activation barriers. A detailed insight into the mechanisms of these motions at the molecular level was obtained using DFT calculations.

The calculated activation parameters for the cyclen-inversion process are in excellent agreement with the experimental ones, including the activation entropies. The activation barriers computed with DFT for the arm rotation pathway present larger deviations from the experimental values. However, we showed that this is mainly due to deficient modelling of solvent effects by PCM as the arm rotation process involves flipping of the negatively charged pendant arms. Propitiously, using a mixed cluster-continuum model that includes two explicit secondsphere water molecules results in activation parameters which are in better agreement with the experiment for the arm rotation process. We believe that the results reported here represent an important contribution to a better understanding the dynamics of these important complexes.

Furthermore, the NMR methodology described here could be, in principle, applied to investigations of the dynamics of complex paramagnetic systems (i.e. proteins with open-shell ions) thanks to the paramagnetically-induced shifts which avoid extensive signal overlap and increase the range of observable exchange rates.

\section{Experimental and computational section}

\subsection{Reagents and materials}

The ligands, $\mathrm{H}_{4}$ dota and $\mathrm{H}_{5}$ do3ap, were prepared according the literature procedures. ${ }^{1,6}$ Samples of the $\mathrm{Eu}^{3+}$ complexes for NMR studies were obtained by dissolving the corresponding ligand $(100 \mathrm{mg})$ in water $(4 \mathrm{~mL})$ and adding 0.95 equiv. of $\mathrm{EuCl}_{3} \cdot 6 \mathrm{H}_{2} \mathrm{O}$. Then, $5 \%$ aq. $\mathrm{LiOH}$ was slowly added to reach $\mathrm{pH} 11$ and the mixture was stirred overnight at $60{ }^{\circ} \mathrm{C}$. The absence of free $\mathrm{Eu}^{3+}$ ions was tested by reaction with xylenol orange in acetate buffer at $\mathrm{pH} 6.7 .^{51}$ The solution was then evaporated to dryness and the residue was re-dissolved in $\mathrm{D}_{2} \mathrm{O}$ (Euriso-top, $99.96 \% \mathrm{D}$ ) for the NMR measurements. The $\mathrm{pD}$ of the samples was adjusted by addition of dilute solutions of $\mathrm{DCl}$ or LiOD in $\mathrm{D}_{2} \mathrm{O}$.

\subsection{NMR spectroscopy}

NMR experiments were performed on a Bruker AVANCE III 600 and $400 \mathrm{MHz}$ spectrometers, the former equipped with a cryoprobe. The temperature of the sample was calibrated using pure $\mathrm{MeOH}$ (below $15{ }^{\circ} \mathrm{C}$ ) and ethylene glycol (above $15^{\circ} \mathrm{C}$ ) by measuring the chemical shift differences between the two ${ }^{1} \mathrm{H}$ NMR signals. ${ }^{52,53}$ Particular care was taken to ensure that the sample reached thermal equilibrium before the data acquisition started. The acquired FID data were then analyzed using MestReNova software. ${ }^{54}$ A $50 \mathrm{~Hz}$ exponential apodization was applied prior to the Fourier transform, followed by phase and baseline corrections. The signals of axial and equatorial protons of both isomers were integrated for the data analysis. In the case of signal overlap, the signal pattern was deconvoluted into Lorenzian-Gaussian curves using MestReNova tools. The dependence of signal integral values with mixing time was fitted using self-written procedures in the MATLAB R2015b ${ }^{\circledR 55}$ environment. The activation enthalpies and entropies $\left(\Delta H^{\ddagger}\right.$ and $\left.\Delta S^{\ddagger}\right)$ were determined using MATLAB by fitting the temperature dependence of exchange rates using the Eyring equation (4).

\subsection{Computational details}

All calculations presented in this work were performed using Gaussian 09 (Revision D.01). ${ }^{56}$ Full geometry optimizations of transition states and energetic minima were performed employing DFT within the meta-GGA approximation using $\mathrm{M}^{5} 6^{57}$ exchange-correlation functional. For all atoms except $\mathrm{Eu}^{3+}$, the $6-31+G(d, p)$ basis set was employed. The large core effective core potential of the Stuttgart family (including $46+4 \mathrm{f}^{6}$ electrons in core, ECP52MWB ${ }^{43}$ and the associated (7s6p5d)/ [5s4p3d] basis set were used for $\mathrm{Eu}^{3+}$. An UltraFine integration grid and the default SCF energy convergence threshold $\left(10^{-8}\right)$ were used in all calculations. All the calculations were performed employing a polarization continuum model to account for bulk solvent effects (water) and the solvent accessible 
surface to define the solute cavity. The identities of all stationary points ( 0 imaginary frequencies) and transition states ( 1 imaginary frequency) were confirmed by frequency analysis.

\section{Conflicts of interest}

There are no conflicts of interest to declare.

\section{Acknowledgements}

The investigations were supported by the Czech Science Foundation (16-03156S; to J. B.), by the Grant Agency of Charles University (1076016, to J. B.) and the Ministry of Education of the Czech Republic (LTC 170607, to J. B. and P. H.; project is connected to the EU COST CA15209 Action). Computational resources were provided by the CESNET LM2015042 and the CERIT Scientific Cloud LM2015085, provided under the program "Projects of Large Research, Development, and Innovations Infrastructures”. C. P.-I. thanks Ministerio de Economía y Competitividad (CTQ2013-43243-P) for generous financial support.

\section{Notes and references}

1 J. F. Desreux, Inorg. Chem., 1980, 19, 1319-1324.

2 D. Parker, R. S. Dickins, H. Puschmann, C. Crossland and J. A. K. Howard, Chem. Rev., 2002, 102, 1977-2010.

3 S. Aime, M. Botta, M. Fasano, M. P. M. Marques, C. F. G. C. Geraldes, D. Pubanz and A. E. Merbach, Inorg. Chem., 1997, 36, 2059-2068.

4 F. A. Dunand, S. Aime and A. E. Merbach, J. Am. Chem. Soc., 2000, 122, 1506-1512.

5 L. S. Natrajan, N. M. Khoabane, B. L. Dadds, C. A. Muryn, R. G. Pritchard, S. L. Heath, A. M. Kenwright, I. Kuprov and S. Faulkner, Inorg. Chem., 2010, 49, 7700-7709.

6 J. Rudovský, P. Cígler, J. Kotek, P. Hermann, P. Vojtíšek, I. Lukes, J. A. Peters, L. Vander Elst and R. N. Muller, Chem. - Eur. J., 2005, 11, 2373-2384.

7 M. Purgel, Z. Baranyai, A. de Blas, T. Rodríguez-Blas, I. Bányai, C. Platas-Iglesias and I. Tóth, Inorg. Chem., 2010, 49, 4370-4382.

8 S. Aime, A. Barge, M. Botta, A. S. De Sousa and D. Parker, Angew. Chem., Int. Ed., 1998, 37, 2673-2675.

9 B. C. Webber and M. Woods, Inorg. Chem., 2012, 51, 8576-8582.

10 M. Woods, S. Aime, M. Botta, J. A. K. Howard, J. M. Moloney, M. Navet, D. Parker, M. Port and O. Rousseaux, J. Am. Chem. Soc., 2000, 122, 9781-9792.

11 The Chemistry of Contrast Agents in Medical Magnetic Resonance Imaging, ed. A. Merbach, L. Helm and É. Tóth, John Wiley \& Sons, Ltd, Chichester, UK, 2013.

12 S. Viswanathan, Z. Kovacs, K. N. Green, S. J. Ratnakar and A. D. Sherry, Chem. Rev., 2010, 110, 2960-3018.

13 W. M. Liu, M. Overhand and M. Ubbink, Coord. Chem. Rev., 2014, 273-274, 2-12.
14 U. Brath, S. I. Swamy, A. X. Veiga, C.-C. Tung, F. Van Petegem and M. Erdélyi, J. Am. Chem. Soc., 2015, 137, 11391-11398.

15 T. Krchová, A. Gálisová, D. Jirák, P. Hermann and J. Kotek, Dalton Trans., 2016, 3486-3496.

16 T. Krchová, V. Herynek, A. Gálisová, J. Blahut, P. Hermann and J. Kotek, Inorg. Chem., 2017, 56, 2078-2091.

17 P. Harvey, A. M. Blamire, J. I. Wilson, K.-L. N. A. Finney, A. M. Funk, P. Kanthi Senanayake and D. Parker, Chem. Sci., 2013, 4, 4251-4258.

18 G. Cucinotta, M. Perfetti, J. Luzon, M. Etienne, P. E. Car, A. Caneschi, G. Calvez, K. Bernot and R. Sessoli, Angew. Chem., Int. Ed., 2012, 51, 1606-1610.

19 L. Lumata, A. K. Jindal, M. E. Merritt, C. R. Malloy, A. D. Sherry and Z. Kovacs, J. Am. Chem. Soc., 2011, 133, 8673-8680.

20 R. S. Dickins, S. Gaillard, S. P. Hughes and A. Badari, Chirality, 2005, 17, 357-363.

21 S. P. Babailov, Prog. Nucl. Magn. Reson. Spectrosc., 2008, 52, 1-21.

22 F. K. Kálmán, Z. Baranyai, I. Tóth, I. Bányai, R. Király, E. Brücher, S. Aime, X. Sun, A. D. Sherry and Z. Kovács, Inorg. Chem., 2008, 47, 3851-3862.

23 S. Aime, A. Barge, M. Botta, M. Fasano, J. Danilo Ayala and G. Bombieri, Inorg. Chim. Acta, 1996, 246, 423-429.

24 F. A. Dunand, R. S. Dickins, D. Parker and A. E. Merbach, Chem. - Eur. J., 2001, 7, 5160-5167.

25 M. Elhabiri, S. Abada, M. Sy, A. Nonat, P. Choquet, D. Esteban-Gómez, C. Cassino, C. Platas-Iglesias, M. Botta and L. J. Charbonnière, Chem. - Eur. J., 2015, 21, 6535-6546.

26 M. Mato-Iglesias, T. Rodríguez-Blas, C. Platas-Iglesias, M. Starck, P. Kadjane, R. Ziessel and L. Charbonniére, Inorg. Chem., 2009, 48, 1507-1518.

27 S. P. Babailov, A. G. Coutsolelos, A. Dikiy and G. A. Spyroulias, Eur. J. Inorg. Chem., 2001, 303-306.

28 S. Hoeft and K. Roth, Chem. Ber., 1993, 126, 869-873.

29 V. Jacques and J. F. Desreux, Inorg. Chem., 1994, 33, 4048-4053.

30 O. V. Yazyev, L. Helm, V. G. Malkin and O. L. Malkina, J. Phys. Chem., 2005, 109, 10997-11005.

31 A. Lasoroski, R. Vuilleumier and R. Pollet, J. Chem. Phys., 2014, 141, 14201.

32 A. Lasoroski, R. Vuilleumier and R. Pollet, J. Chem. Phys., 2013, 139, 104115.

33 A. Ramírez-Solís, J. I. Amaro-Estrada, J. Hernández-Cobos and L. Maron, J. Phys. Chem. A, 2017, 121, 2293-2297.

34 R. Pollet, N. N. Nair and D. Marx, Inorg. Chem., 2011, 50, 4791-4797.

35 U. Cosentino, A. Villa, D. Pitea, G. Moro, V. Barone and A. Maiocchi, J. Am. Chem. Soc., 2002, 124, 4901-4909.

36 C. Platas-Iglesias, Eur. J. Inorg. Chem., 2012, 2023-2033.

37 M. P. M. Marques, C. F. G. C. Geraldes, A. D. Sherry, A. E. Merbach, H. Powell, D. Pubanz, S. Aime and M. Botta, J. Alloys Compd., 1995, 225, 303-307.

38 C. Kumas, W. S. Fernando, P. Zhao, M. Regueiro-Figueroa, G. E. Kiefer, A. F. Martins, C. Platas-Iglesias and A. D. Sherry, Inorg. Chem., 2016, 55, 9297-9305. 
39 K. Stott, J. Stonehouse, J. Keeler, T.-L. Hwang and A. J. Shaka, J. Am. Chem. Soc., 1995, 117, 4199-4200.

40 S. Aime, L. Barbero, M. Botta and G. Ermondi, J. Chem. Soc., Dalton Trans., 1992, 225-228.

41 L. Liu and Q. X. Guo, Chem. Rev., 2001, 101, 673-695.

42 M. Dolg, H. Stoll and H. Preuss, Theor. Chim. Acta, 1993, 85, 441-450.

43 M. Dolg, H. Stoll, A. Savin and H. Preuss, Theor. Chim. Acta, 1989, 75, 173-194.

44 A. Roca-Sabio, M. Regueiro-Figueroa, D. Esteban-Gómez, A. de Blas, T. Rodríguez-Blas and C. Platas-Iglesias, Comput. Theor. Chem., 2012, 999, 93-104.

45 M. R. Spirlet, J. Rebizant, J. F. Desreux and M. F. Loncin, Inorg. Chem., 1984, 23, 359-363.

46 M. Regueiro-Figueroa, B. Bensenane, E. Ruscsák, D. EstebanGómez, L. J. Charbonnière, G. Tircsó, I. Tóth, A. de Blas, T. Rodríguez-Blas and C. Platas-Iglesias, Inorg. Chem., 2011, 50, 4125-4141.

47 G. Brehm, M. Reiher and S. Schneider, J. Phys. Chem. A, 2002, 106, 12024-12034.
48 D. Esteban-Gómez, A. de Blas, T. Rodríguez-Blas, L. Helm and C. Platas-Iglesias, ChemPhysChem, 2012, 13, 3640-3650.

49 M. Regueiro-Figueroa and C. Platas-Iglesias, J. Phys. Chem. A, 2015, 119, 6436-6445.

50 R. Pollet, C. S. Bonnet, P. Retailleau, P. Durand and É. Tóth, Inorg. Chem., 2017, 56, 4317-4323.

51 A. Barge, G. Cravotto, E. Gianolio and F. Fedeli, Contrast Media Mol. Imaging, 2006, 1, 184-188.

52 C. Ammann, P. Meier and A. Merbach, J. Magn. Reson., 1982, 46, 319-321.

53 M. L. Kaplan, F. A. Bovey and H. N. Cheng, Anal. Chem., 1975, 47, 1703-1705.

54 MestReNova, Version 11.0.1-17801, Mestrelab Research S.L., Santiago de Compostela, 2016.

55 MATLAB and Optimisation Toolbox 7.3 Release R2015b, The MathWorks, Inc., Natick, Massachusetts, United States, DERIVESTsuite, available via www.mathworks.com.

56 Gaussian 09, Revision D.01, Gaussian, Inc., Wallingford, CT, 2016. 57 Y. Zhao and D. G. Truhlar, Theor. Chem. Acc., 2008, 120, 215-241. 